\title{
Reduced Graphene Oxide/Ruthenium Oxide Hexacyanoferrate Nanocomposite for Electrochemical Determination of Ethanol in Commercial Samples
}

\author{
Pedro H. S. Borges ${ }^{a}$ and Edson Nossol ${ }^{\circledR} * a$ \\ ${ }^{a}$ Instituto de Química, Universidade Federal de Uberlândia, 38400-902 Uberlândia-MG, Brazil
}

\begin{abstract}
Reduced graphene oxide/ruthenium oxide hexacyanoferrate (rGO/RuOHCF) modified electrode showed synergic activity between the materials attested by the increase of electrochemical current and stability. The preparation of the nanocomposite was made by a simple two-step electrochemical approach. The material structure was characterized by spectroscopic techniques (Raman, infrared and energy-dispersive X-ray) as well as its morphology by scanning electron microscopy and compared to the analogously prepared reduced graphene oxide (rGO) and ruthenium oxide hexacyanoferrate (RuOHCF) thin films spectra and images. The results suggest that the improvement of the nanocomposite electrochemical activity is generated by the well-distributed RuOHCF nanometric particles over high-surfaced graphene sheets. Ethanol electrochemical oxidation in the $\mathrm{rGO} / \mathrm{RuOHCF}$ modified electrode was performed in $0.1 \mathrm{~mol} \mathrm{~L}^{-1} \mathrm{NaCl}(\mathrm{pH}=1.5)$ solution and it showed an anodic current peak starting at $0.9 \mathrm{~V}$. Scan rate tests exhibited a diffusioncontrolled process not followed by any coupled chemical reaction. The determination of ethanol by amperometry coupled with batch injection analysis (BIA) system resulted in a wide linear range (20-400 $\left.\mathrm{mmol} \mathrm{L}^{-1}\right)$ and good sensitivity $\left(0.150 \mu \mathrm{A} \mathrm{L} \mathrm{mmol}^{-1}\right)$. The nanocomposite also showed application as an electrochemical sensor of ethanol in commercial samples mainly because of its easy preparation comparing to biosensors.
\end{abstract}

Keywords: ruthenium Prussian Blue analogue, carbon nanomaterial, hexacyanoferrate particles, batch injection analysis

\section{Introduction}

The development of ethanol sensors must be accurate and sensitive due to its utility in many different areas. Forensic and medical fields require this substance quantity measurement for many kinds of biological samples as urine, blood, sweat, and others. ${ }^{1-4}$ Nowadays, due to the coronavirus disease 2019 (COVID-19) pandemic, the use of ethanol as a general-purpose disinfectant has increased on a large scale, so it is very important to attest the quality of the product. Besides these, agricultural, environmental and food industries need quick and precise analysis methods for ethanol monitoring in diverse aqueous samples. ${ }^{5-7}$ Since 1975 , Brazil motivates ethanol production based on the fermentation and distillation of sugarcane juice for its utilization as an alternative fuel in its anhydrous form or diluted in gasoline matrix and also in beverage production, principally for a highly consumed liquor based on sugarcane called cachaça. ${ }^{8,9}$

The ethylic alcohol concentration can be evaluated by various methods such as mass spectroscopy, ${ }^{10}$ liquid

*e-mail: enossol@ufu.br chromatography, ${ }^{11}$ gas chromatography, ${ }^{12}$ refractometry, ${ }^{13}$ Raman spectroscopy, ${ }^{14}$ nuclear magnetic resonance, ${ }^{15}$ and electrochemistry. ${ }^{16,17}$ The latter technique, comparing to the others, shows a lower cost and simplified instrumentation ${ }^{18,19}$ which are desirable characteristics for ethanol content analysis mainly in simpler matrixes such as commercial alcohol and distilled drinks. Furthermore, the sensitivity, speed, and reagent savings can be easily improved by using the batch injection analysis (BIA) system..$^{20,21}$ This accessory was developed by Wang and Taha ${ }^{22}$ based on flow injection analysis systems without the use of pipes and valves, which eliminates issues caused by bubbles or flow obstructions. ${ }^{23}$ The procedure consists of the injection of small volumes of sample close and directly on the electrode surface, which is immersed in a great amount of supporting electrolyte. This scheme is called wall-jet. Its hydrodynamics fundaments combined to the huge dilution of the sample are the key of the BIA systems remarkable attributes. ${ }^{24}$ Moreover, the instrumentation set provides the possibility to run on-site analysis when coupled to a portable potentiostat. ${ }^{25}$

The electroanalytical field provides the possibility of using various materials in the electrode surface enhancing 
the sensitivity and stability supported by adequate selectivity. Graphene, a two-dimensional structure of $\mathrm{sp}^{2}$ carbon atoms, is a promising option as a modifier agent mainly because of its high surface area and electrical conductivity. ${ }^{26}$ For electroanalytical measurements these properties favor the charge transfer although in primitive graphene the electrocatalytic activity is not so prominent. An alternative to solve that problem is to use a derivative of graphene with functional oxygen groups in its framework. ${ }^{27}$ This material, called graphene oxide (GO), is hydrophilic because of the presence of oxygen grouping, generating defects that are highly reactive sites and can promote the electrocatalysis of several chemical species. ${ }^{28,29}$ The high amount of defects can harm the electron transfer, so it is important to produce a structure with very significant $\mathrm{sp}^{2}$ carbon atoms. This procedure can be performed by reducing $\mathrm{GO}$, and it can be made by some techniques such as electrochemical, ${ }^{30}$ chemical,${ }^{31}$ or thermal ${ }^{32}$ routes. The former technique, in contrast to the others, shows simplicity, quickness, lower-cost and toxic reactants-free. The electrochemical reduction of GO can be performed by the application of an appropriate potential in an aqueous GO dispersion to control the procedure, eliminating the oxygen functional groups and depositing a solid and conductive material in the working electrode surface..$^{30}$ Another advantage of using this method is the possibility to reduce other species simultaneously, generating nanocomposites and improving its electrocatalytic properties for analytical purposes. ${ }^{33,34}$ Anyway, graphene-based composites are largely used materials for determination of several kinds of chemical species. ${ }^{35-39}$

The Prussian Blue analogues are face-centered cubic structured compounds with multivalent metal sites octaedrically coordinated by cyano groups which general formula can be demonstrated by $\mathrm{A}_{\mathrm{a}} \mathrm{M}_{\mathrm{m}}\left[\mathrm{M}_{\mathrm{n}}^{\prime}(\mathrm{CN})_{6}\right] \cdot \mathrm{kH}_{2} \mathrm{O}$, where $\mathrm{a}, \mathrm{m}, \mathrm{n}$, and $\mathrm{k}$ are stoichiometric numbers, $\mathrm{M}$ and M' are transition metals and A is, generally, an alkali metal ion. ${ }^{40}$ These compounds are abundantly used in electrocatalysis as electrochemical sensors mainly because of their stability and reversibility. ${ }^{41,42}$ As well as reduced graphene oxide, metal hexacyanoferrates can be produced by electrochemical method applying adequate electrical potential in the presence of potassium ferricyanide and a metal salt. ${ }^{41}$ Particularly, the ruthenium oxide hexacyanoferrate is an excellent electrocatalyst material because of its wide active potential range and it is capable to mediate oxidation and/or reduction of several kinds of species. ${ }^{43-45}$ Moreover, in that Prussian Blue analogue, oxygen atoms are acting as bridges in the structure, promoting an enhancement in electrochemical stability ${ }^{45}$ and complementing a set of ideal properties for modifying agents in electrode surfaces. After all, these characteristics can, even more, be upgraded if metal hexacyanoferrate nanoparticles are produced over highly conductive graphene sheets with a large surface area. ${ }^{46}$

The aiming of this work is to produce a nanocomposite based on reduced graphene oxide decorated with ruthenium oxide hexacyanoferrate ( $\mathrm{rGO} / \mathrm{RuOHCF})$ using a two-step electrochemical approach. The material of interest is compared with its isolated components by several characterization methods for better elucidation of its composition. Furthermore, the nanocomposite electrocatalytic activity is tested for ethanol oxidation by amperometry using the convenient BIA system, which enables the composition prediction of the analyte in commercial samples.

\section{Experimental}

\section{Chemicals}

All the solutions and dispersions were prepared using deionized water (resistivity $\geq 18 \mathrm{M} \Omega \mathrm{cm}$ ) obtained in a Milli-Q water purification system (Millipore, Bedford, Massachusetts, USA). Ruthenium chloride, chloride acid, and sodium phosphate dibasic were acquired from SigmaAldrich (St. Louis, Missouri, USA) and graphite oxide $(90 \%, \mathrm{~m} / \mathrm{m})$ from CN Shanghai (Shanghai, China). Sodium hydroxide $(97 \%, \mathrm{~m} / \mathrm{m})$ was purchased from Quimex (São Paulo, São Paulo, Brazil) and potassium ferricyanide (99\%, $\mathrm{m} / \mathrm{m}$ ) from Panreac (Castellar del Vallès, Barcelona, Spain). Sodium chloride $(99 \%, \mathrm{~m} / \mathrm{m}$ ) was obtained from Vetec (São Paulo, São Paulo, Brazil) as well as phosphoric acid (85\%, v/v), and ethanol (99.8\%, v/v) was obtained from Synth (Diadema, São Paulo, Brazil).

Instrumentation

Electrochemical measurements were controlled through NOVA 2.1 software in a microcomputer connected to an AutoLab PGSTAT 12 potentiostat/galvanostat (Metrohm AutoLab B. V., Utrecht, Netherlands). As counter electrode, it was used a platinum wire and as reference electrode, an $\mathrm{Ag}_{(\mathrm{s})} / \mathrm{AgCl}_{(\mathrm{s})} / \mathrm{Cl}^{-}{ }_{(\mathrm{aq})}\left(\mathrm{KCl} 3 \mathrm{~mol} \mathrm{~L}^{-1}\right)$ lab-made microelectrode. ${ }^{47}$ The material was synthesized over a working glassy carbon electrode (GCE) for electrochemical measurements and over a fluorine-doped tin oxide (FTO) glass for characterization techniques.

Raman spectroscopy was performed in a LabRAM HR Evolution microscope (HORIBA, Kyoto, Japan) using a $633 \mathrm{~nm}$ argon ion laser with $10 \%$ incidence potency. The Fourier transform infrared (FTIR) spectra were obtained 
by a Frontier MIR/FIR from PerkinElmer (Waltham, USA) coupled to a diamond-equipped attenuated total reflectance (ATR) accessory from Pike Technologies (Madison, USA). Thin films images were acquired by scanning electron microscopy (SEM) on a Vega 3 microscope (Tescan, Czech Republic) operated at $20 \mathrm{kV}$ and elemental analysis were obtained by energy-dispersive $\mathrm{X}$-ray spectroscopy (EDX) technique using an INCA X-Act (Oxford Instruments, Abingdon, UK) detector. The particle size on nanocomposite was estimated by the measurement of 100 nanoparticles utilizing the ImageJ software. ${ }^{48}$

\section{Thin films synthesis}

The treatment of glassy carbon electrode was made by polishing the surface in an alumina power $(0.3 \mu \mathrm{m})$ suspension followed by a deionized water rinsing and then put in water/ethanol (1:1) solution for 5 min sonication.

The $\mathrm{rGO} / \mathrm{RuOHCF}$ nanocomposite was entirely fabricated by the cyclic voltammetry (CV) method. The first step consists in the three-electrode system immersed in a 10 -min sonicated $10 \mathrm{~mL}$ dispersion $(\mathrm{pH}=3.0)$ containing $0.1 \mathrm{mg} \mathrm{mL}^{-1}$ graphene oxide, $1.0 \mathrm{mmol} \mathrm{L}^{-1} \mathrm{RuCl}_{3}$ and $0.05 \mathrm{~mol} \mathrm{~L}^{-1} \mathrm{Na}_{2} \mathrm{HPO}_{4}$ as supporting electrolyte and then 10 voltammetric cycles, at $20 \mathrm{mV} \mathrm{s}^{-1}$, from 0 to $-1.5 \mathrm{~V}$ were applied for $\mathrm{rGO} / \mathrm{RuO}_{\mathrm{x}}$ precursor deposition. Secondly, after dried at room temperature, this modified electrode was submitted to 8 voltammetric cycles, at $100 \mathrm{mV} \mathrm{s}^{-1}$, from -0.3 to $1.3 \mathrm{~V}$ in a solution $(\mathrm{pH}=1.5)$ containing $0.1 \mathrm{~mol} \mathrm{~L}^{-1}$ $\mathrm{NaCl}$ and $1.0 \mathrm{mmol} \mathrm{L}^{-1} \mathrm{~K}_{3}\left[\mathrm{Fe}(\mathrm{CN})_{6}\right]$ for nanoparticle composition modification. The $\mathrm{pH}$ was adjusted using a concentrated $\mathrm{H}_{3} \mathrm{PO}_{4}$ solution for the first step while for the second step a concentrated $\mathrm{HCl}$ solution was used. These acidic species were chosen to alter $\mathrm{pH}$ keeping the same anion from the supporting electrolyte in the composition of the solutions.

The rGO thin film was obtained the same way as $\mathrm{rGO} / \mathrm{RuOHCF}$ nanocomposite, however, in the absence of $\mathrm{RuCl}_{3}$, whereas the RuOHCF thin film preparation was in absence of GO precursor. The preparation of all materials was made at room temperature and in the presence of oxygen.

\section{Ethanol electrochemical determination}

The determination of ethanol based on its electrochemical oxidation in $\mathrm{rGO} / \mathrm{RuOHCF}$ modified electrode was performed by amperometry technique coupled to a batch injection analysis system. The BIA cell was constituted by a $200 \mathrm{~mL}$ capacity cylindrical glass and it has a top cover with holes on the edges for a mechanical stirrer and for reference and counter electrodes. At the center of the same cover, there is an orifice for a micropipette tip accommodation at $2 \mathrm{~mm}$ distanced of the working electrode, which is accommodated in the bottom cover. ${ }^{49}$ This configuration generates current peak signals that are proportional to the analyte concentration and it is known as "wall-jet". ${ }^{22}$

The $\mathrm{rGO} / \mathrm{RuOHCF}$ modified electrode was prepared using 20 voltammetric cycles in $0.1 \mathrm{~mol} \mathrm{~L}^{-1} \mathrm{NaCl}$ $(\mathrm{pH}=1.5)$ for current stabilization before all measurements. No buffer was needed due to high difference between analyte and supporting electrolyte concentrations, once $\mathrm{EtOH}$ is incapable to variate this $\mathrm{pH}$ magnitude. The analytical curve was obtained by the injection of prepared ethanol solutions with well-known concentrations in the supporting electrolyte. The injections in the BIA cell were performed with an Eppendorf Multipette ${ }^{\circledR}$ stream electronic pipette attached to a Multipette ${ }^{\circledR}$ Combitip $^{\circledR}$. A previous optimization of the applied potential $(0.8,0.9,1.0,1.1$, and 1.2 V), dispensing speed (78.1, 164.0, 213.0, 277.0, and $\left.370.0 \mu \mathrm{L} \mathrm{s}^{-1}\right)$, and dispensing volume $(20,40,60,80$, and $100 \mu \mathrm{L}$ ) were carried out by fixing two of the three parameters at the median value and collecting the response of the current peak with the highest intensity and lowest relative standard deviation (RSD). The commercial alcohol and cachaça samples were simply diluted in supporting electrolyte containing $50.0 \mathrm{mmol} \mathrm{\textrm {L } ^ { - 1 }}$ of standard ethanol and were injected at the end of the analytical curve. All the BIA measurements were performed under mechanical stirring.

\section{Results and Discussion}

\section{rGO/RuOHCF nanocomposite synthesis}

The preparation of the $\mathrm{rGO} / \mathrm{RuOHCF}$ nanocomposite was performed in two steps but using the same technique. A 10 -cycles voltammetry, at $20 \mathrm{mV} \mathrm{s}^{-1}$, from 0 to $-1.5 \mathrm{~V}$ was applied on the three-electrode system immersed in the GO dispersion $(\mathrm{pH}=3$ ) containing the ruthenium chloride as nanoparticle source and the supporting electrolyte under magnetic stirring. This first step, shown in Figure 1a, generated a voltammogram with an irreversible cathodic peak which is related to the reduction of GO, while the relative increase in each cycle can be associated with the quantity of conductor material depositing in the working electrode surface..$^{50}$ The acid media, although it stimulates the hydrogen evolution around $-1.5 \mathrm{~V}$, promotes the protonation of the oxygen-containing groups of $\mathrm{GO}$, which plays an important role on the reduction process kinetics. ${ }^{51}$ So the constant stirring during the electrodeposition helps removing generated hydrogen gas bubbles competing for 
sites on the electrode surface. ${ }^{52}$ Also a cathodic peak at $-0.5 \mathrm{~V}$ is perceived, which is related to the reduction of $\mathrm{Ru}^{3+}$ to metallic and oxy-chloro ruthenium species that, in the successive scans, are converted to hydroxyl and/or oxy-abundant $\mathrm{Ru}$ species. ${ }^{53}$ The low $\mathrm{pH}$ of the dispersion avoids previous precipitation of ruthenium hydroxide and keeps the $\mathrm{Ru}^{3+}$ available for the electrochemical reduction. ${ }^{54}$

The product of the first step, a nanocomposite containing rGO and ruthenium oxide species, was dried at room temperature and submitted to a second procedure. This step consists of the immersion of the previously modified electrode in a solution $(\mathrm{pH}=1.5)$ containing potassium ferricyanide and sodium chloride as supporting electrolyte for nanoparticle structural modification. The low $\mathrm{pH}$ level was chosen to increase the dissociation of ferricyanide, resulting in faster nucleation kinetics, and as consequence to increase the formation of RuOHCF. ${ }^{55,56}$ Moreover, at higher electrochemical potentials and more acidic media the stripping of ruthenium nanoparticles is favored.$^{57}$ From -0.3 to $1.3 \mathrm{~V}, 8$ scans at $100 \mathrm{mV} \mathrm{s}^{-1}$ are performed for the desirable nanocomposite fabrication which voltammogram can be checked in Figure 1b. A reaction between the oxide nanoparticles and ferricyanide happens in the first scans forming the RuOHCF nanoparticles. The saturation of these species is reached in the final scans, generating a typical electrochemical profile of the Prussian Blue analogue with characteristic redox pairs. ${ }^{43}$

\section{Electrochemical studies}

The electrochemical profile between 0.3 and $1.25 \mathrm{~V}$ of the $\mathrm{rGO} / \mathrm{RuOHCF}$ nanocomposite was compared to analogously prepared rGO and RuOHCF thin films and it is shown in Figure 2a. The isolated RuOHCF film shows three well-defined redox pairs which are assigned to ruthenium and iron electron transfer processes: at $-0.05 \mathrm{~V}$ the reaction is related to $\mathrm{Ru}^{\mathrm{II}} \mathrm{O}\left[\mathrm{Fe}^{\mathrm{II}}(\mathrm{CN})_{6}\right] / \mathrm{Ru}^{\mathrm{II}} \mathrm{O}\left[\mathrm{Fe}^{\mathrm{II}}(\mathrm{CN})_{6}\right]$, at $0.9 \mathrm{~V}$ is related to $\mathrm{Ru}^{\mathrm{III}} \mathrm{O}\left[\mathrm{Fe}^{\mathrm{III}}(\mathrm{CN})_{6}\right] / \mathrm{Ru}^{\mathrm{IV}} \mathrm{O}\left[\mathrm{Fe}^{\mathrm{III}}(\mathrm{CN})_{6}\right]$ and at $1.1 \mathrm{~V}$

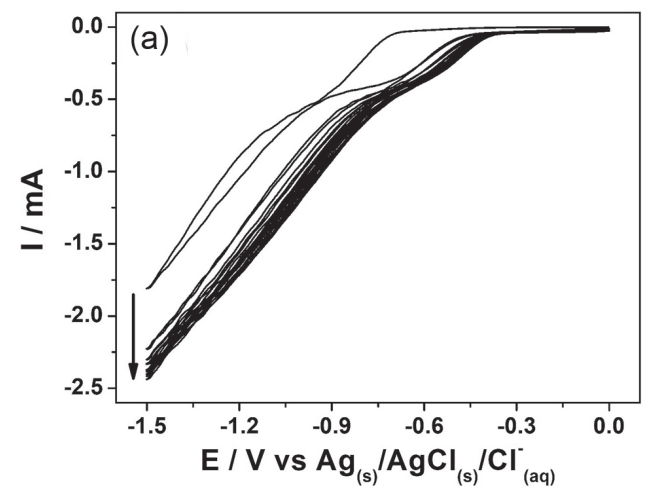

is related to $\mathrm{Ru}^{\mathrm{IV}} \mathrm{O}\left[\mathrm{Fe}^{\mathrm{III}}(\mathrm{CN})_{6}\right] / \mathrm{Ru}^{\mathrm{VI}} \mathrm{O}\left[\mathrm{Fe}^{\mathrm{III}}(\mathrm{CN})_{6}\right] .^{46}$ The system electroneutrality is established by the diffusion of sodium ion in the framework. The rGO cyclic voltammogram shows a pseudo-capacitive behavior with a redox pair at $0.3 \mathrm{~V}$ attributed to functional oxygen groups that are too stable for elimination by the electrochemical method. ${ }^{50}$ The presence of the characteristic redox pairs joining the increase of current intensity suggests the successful attachment of the RuOHCF nanoparticles to ample-area graphene sheets forming a nanocomposite with high synergic action.

$\mathrm{RGO} / \mathrm{RuOHCF}$ and RuOHCF films had their stability tested in $0.1 \mathrm{~mol} \mathrm{~L}^{-1} \mathrm{NaCl}$ supporting electrolyte with $\mathrm{pH}$ of $1.5,4.0,7.0$, and 9.0 between -0.3 and $1.25 \mathrm{~V}$. Figures $2 \mathrm{~b}$ and $2 \mathrm{c}$ show the decrease of the relative current of the anodic peak at $1.1 \mathrm{~V}$ during 50 scans of RuOHCF and $\mathrm{rGO} / \mathrm{RuOHCF}$, respectively, and it demonstrates that the nanocomposite owns better stability in all $\mathrm{pH}$ values. This effect can be explained by the reduced graphene oxide supporting structure that, in addition to offering an increase of surface area and better electron transferring, it promotes more effectiveness of the Prussian Blue analogue nanoparticles attachment. ${ }^{58}$ The lower $\mathrm{pH}$ value showed better stability during the cycles since higher $\mathrm{pH}$ values favor the precipitation of the ruthenium in its hydroxide form. ${ }^{54}$ Therefore, the $\mathrm{pH}$ of 1.5 was chosen to be used in the next stages of the work.

\section{Characterization}

The three different materials, $\mathrm{rGO}, \mathrm{RuOHCF}$, and $\mathrm{rGO} /$ RuOHCF were submitted to a $633 \mathrm{~nm}$ argon ion laser to acquire Raman spectra that are shown in Figure 3a. For the $\mathrm{RuOHCF}$, the typical $\mathrm{C} \equiv \mathrm{N}$ stretching of the Prussian Blue analogues ${ }^{59}$ appears at $2137 \mathrm{~cm}^{-1}$ and it is also present in the nanocomposite spectrum. Materials based on reduced graphene oxide have two main characteristic signals: the $\mathrm{D}$ and $\mathrm{G}$ bands. The former, around $1348 \mathrm{~cm}^{-1}$, is related to defects on the $\mathrm{sp}^{2}$ network generated during oxidation/

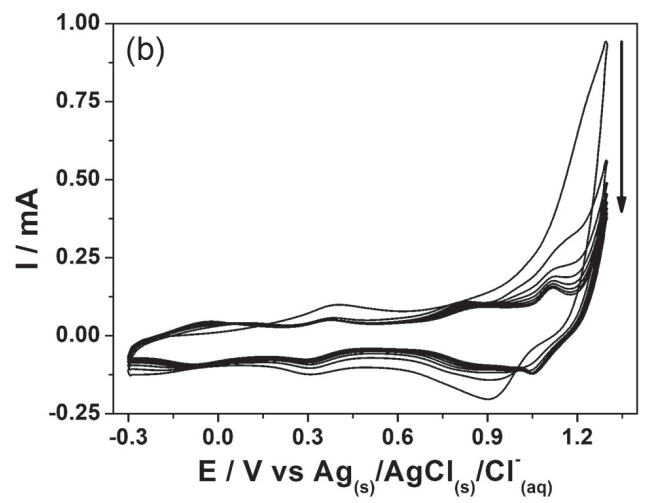

Figure 1. (a) Simultaneous electrochemical reduction of $\mathrm{GO}$ and $\mathrm{Ru}^{3+}$; (b) $\mathrm{rGO} / \mathrm{RuOHCF}$ film formation. 

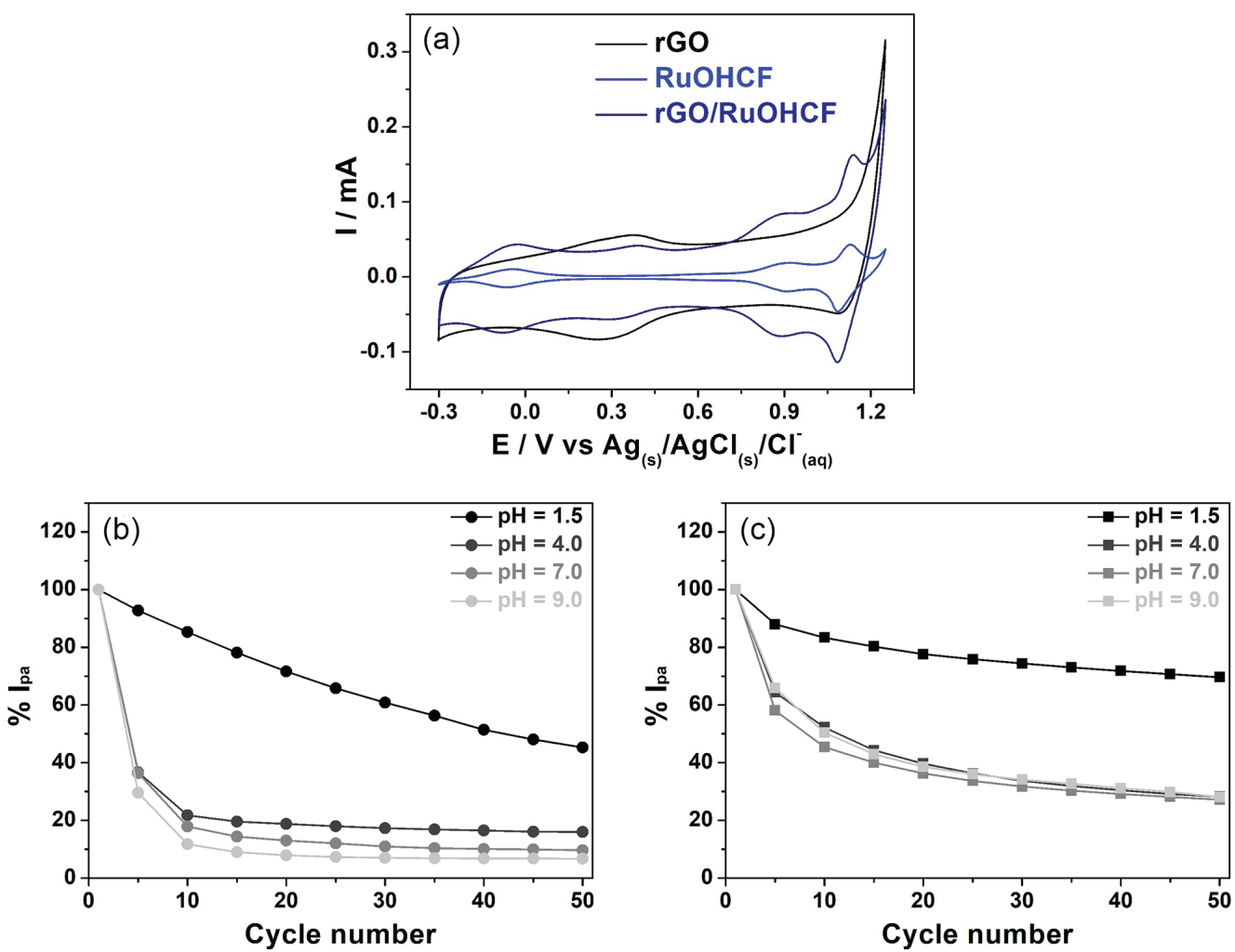

Figure 2. (a) Electrochemical profile of the thin films in $0.1 \mathrm{~mol} \mathrm{~L}^{-1} \mathrm{NaCl}(\mathrm{pH}=1.5)$; electrochemical stability for $50 \mathrm{scans}$ in $0.1 \mathrm{~mol} \mathrm{\textrm {L } ^ { - 1 }} \mathrm{NaCl}_{\mathrm{of}}$ (b) $\mathrm{RuOHCF}$ and (c) rGO/RuOHCF.

reduction synthesis of the material, while the latter, around $1584 \mathrm{~cm}^{-1}$, is associated with first-order scattering of the $\mathrm{E}_{2 \mathrm{~g}}$ symmetry and represents the in-plane vibration of the $\mathrm{sp}^{2}$ carbon bonds. ${ }^{60}$ The ratio between the area of the D and $G$ bands $\left(\mathrm{I}_{\mathrm{D}} / \mathrm{I}_{\mathrm{G}}\right)$ informs the degree of defects of the carbonaceous structures, presenting a value of 3.2 for $\mathrm{rGO}$ and 2.4 for $\mathrm{rGO} / \mathrm{RuOHCF}$ films spectra. The decrease of the ratio in the nanocomposite indicates the reconstitution of the $\mathrm{sp}^{2}$ carbon sites in the presence of the simultaneouslyreduced nanoparticles. ${ }^{61,62}$ The concurrent appearance of all the discussed bands in the Raman spectrum of the $\mathrm{rGO} / \mathrm{RuOHCF}$ attest to the successful formation of the nanocomposite material.

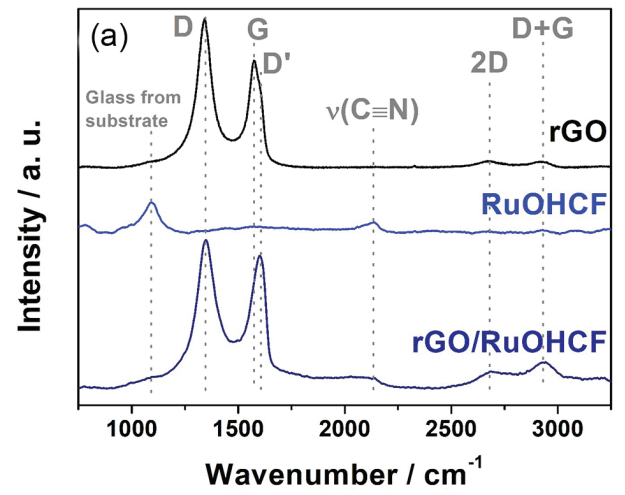

Figure 3. (a) Raman and (b) infrared (ATR) spectra of the thin films.
Figure $3 \mathrm{~b}$ shows the FTIR spectra for all the obtained films. The sharp band related to the cyanide group ${ }^{63}$ stretching mode appears at $2070 \mathrm{~cm}^{-1}$ in the RuOHCF film spectrum which is also present in the nanocomposite film spectrum. The rGO spectrum exhibits, around $1550 \mathrm{~cm}^{-1}$, a band associated with the $\mathrm{C}=\mathrm{C}$ bond of the structural framework. Besides that, some bands related to the functional oxygen groups derived from the oxidation of the graphite is also shown, such as $\mathrm{C}-\mathrm{O}$ (at 1370 and $1430 \mathrm{~cm}^{-1}$ ) and $\mathrm{C}=\mathrm{O}$ stretching (at 1645 and $\left.1705 \mathrm{~cm}^{-1}\right) \cdot{ }^{64}$ All discussed bands can be perceived in the $\mathrm{rGO} / \mathrm{RuOHCF}$ spectrum, which suggests the presence of the two materials in the same structure, composing the nanocomposite framework.

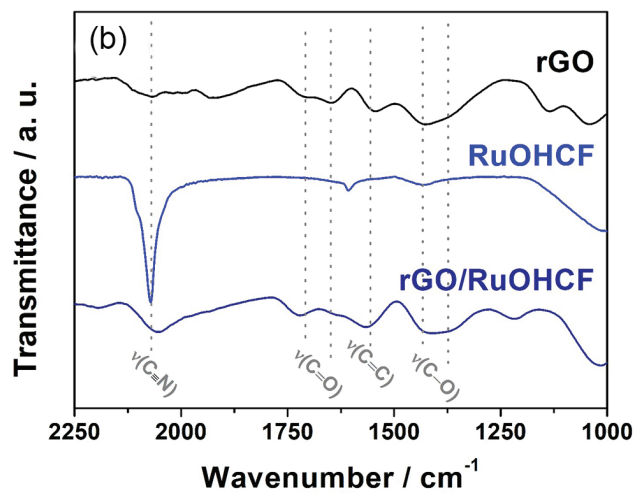


Surface morphology studies were made through SEM images and it is shown in Figure 4. rGO film exhibited wrinkled sheet-like morphology caused by defects and functional groups on its two-dimensional structure and this roughness implies a sharp increase of surface area. ${ }^{65}$ Isolated-prepared RuOHCF film showed several nanoparticles that trend to form agglomerates micrometric-scaled. This effect does not happen in the $\mathrm{rGO} / \mathrm{RuOHCF}$ nanocomposite, since the carbonaceous material acts as a nucleation center preventing the grown of the particles and keeping them well-dispersed over graphene sheets. ${ }^{66}$ The size of the RuOHCF nanoparticles in the $\mathrm{rGO} / \mathrm{RuOHCF}$ film was estimated to $89.3 \mathrm{~nm}$ on average.

The elemental composition of the films was analyzed by EDX and the spectra are shown in Figure 5. All of them had the presence of $\mathrm{Sn}$ and $\mathrm{Si}$, which constitutes the structure of the FTO substrate. Sodium and phosphorous also appeared on the spectra and they have remained from the supporting electrolyte of the first step of the synthesis. rGO film showed the expected abundant $\mathrm{C}$ signal and the $\mathrm{O}$ signal from the functional oxygen groups. RuOHCF film exhibited a lower $\mathrm{C}$ signal because of the absence of the carbonaceous material and it has the same intensity of $\mathrm{N}$ signal, which constitutes the cyanide ligand from the Prussian Blue analogue structure. The presence of Ru and

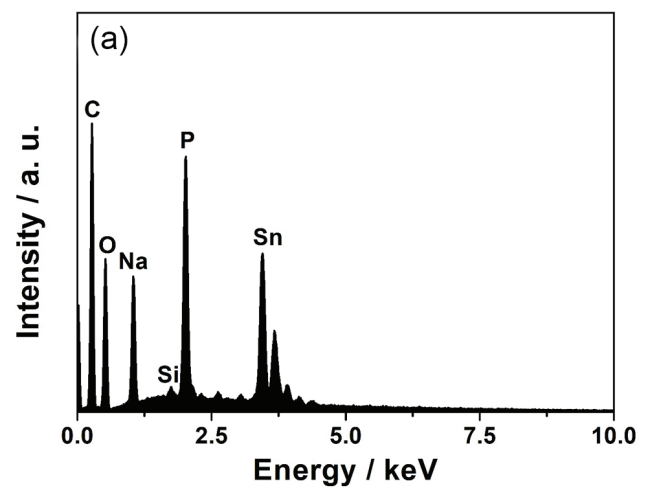

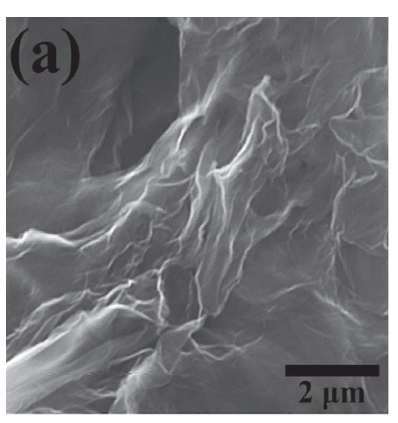
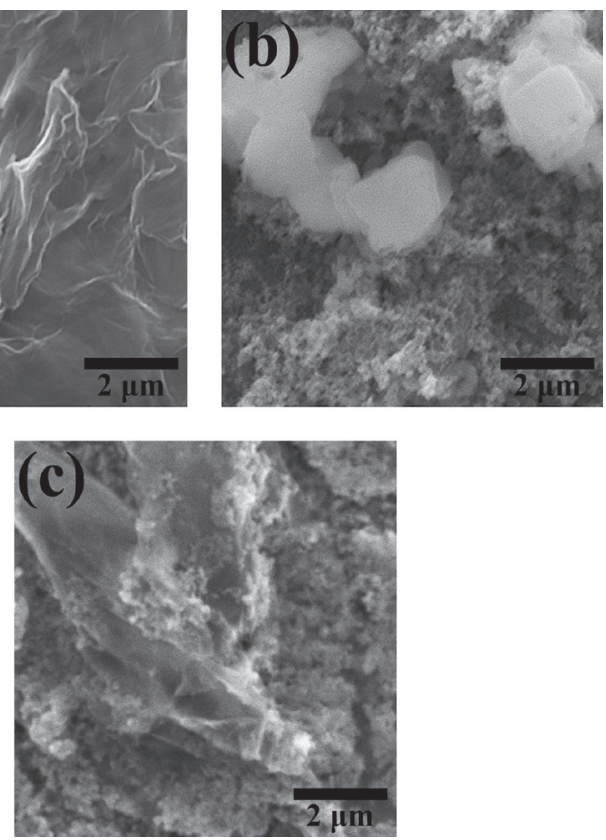

Figure 4. SEM images of (a) rGO, (b) RuOHCF, and (c) rGO/RuOHCF thin films.

Fe signals are also shown as well as in the $\mathrm{rGO} / \mathrm{RuOHCF}$ spectrum. The rise of the $\mathrm{C}$ signal in the $\mathrm{rGO} / \mathrm{RuOHCF}$ spectrum and the appearance of the signals mentioned above suggests the presence of the carbon framework supporting the well-dispersed nanoparticles.

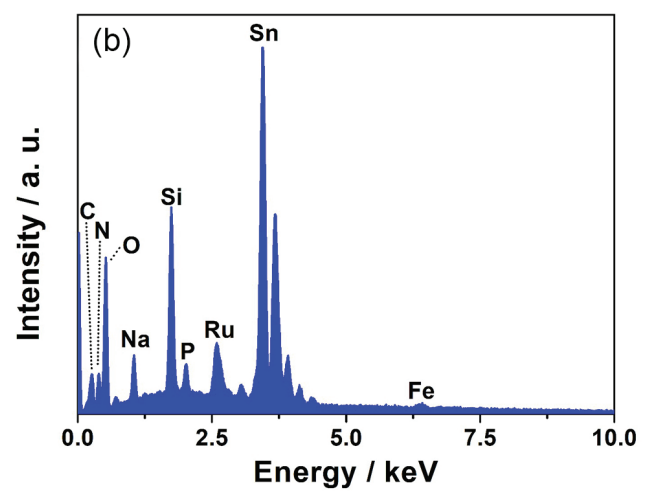

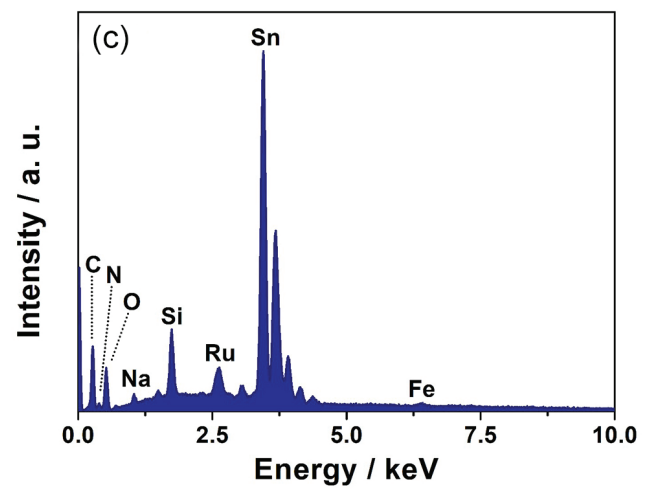

Figure 5. EDX spectra of (a) rGO, (b) RuOHCF and (c) rGO/RuOHCF thin films. 


\section{Ethanol electrochemical determination}

The electrochemical behavior of ethanol in the $\mathrm{rGO} / \mathrm{RuOHCF}$ modified electrode was studied in the optimized media discussed previously. A supporting electrolyte of $0.1 \mathrm{~mol} \mathrm{~L}^{-1} \mathrm{NaCl}(\mathrm{pH}=1.5)$ was used for all electrochemical tests for ethanol electro-oxidation. The voltammetric profiles of the analyte on the modified and glassy carbon electrodes are shown in Figure 6a and attest an increase of anodic current starting at $0.9 \mathrm{~V}$ for $\mathrm{rGO} / \mathrm{RuOHCF}$, which corresponds to the electrochemicalstimulated oxidation of ethanol. The glassy carbon electrode did not present activity for ethanol oxidation in this range of potential. The reaction mediated by the Prussian Blue analogue part of the nanocomposite can be proposed by equation $1:^{46,67}$

$$
\begin{aligned}
& \mathrm{rGO} / \mathrm{Ru}^{\mathrm{VI}} \mathrm{O}\left[\mathrm{Fe}(\mathrm{CN})_{6}\right]+\mathrm{CH}_{3} \mathrm{CH}_{2} \mathrm{OH} \rightarrow \\
& \quad \mathrm{rGO} / \mathrm{Ru}^{\mathrm{IV}} \mathrm{O}\left[\mathrm{Fe}(\mathrm{CN})_{6}\right]+\mathrm{CH}_{3} \mathrm{CHO}+2 \mathrm{H}^{+}+2 \mathrm{e}^{-}
\end{aligned}
$$

The behavior of the electrochemical reaction was also studied by scan rate test between 25 and $300 \mathrm{mV} \mathrm{s}^{-1}$, and the voltammograms are shown in Figure $6 \mathrm{~b}$. The intensity of the anodic peak current around $1.1 \mathrm{~V}$ increases linearly with the increasing of the square of the scan rate (Figure 6c), which implies in a diffusion-controlled process. ${ }^{68}$ The reaction
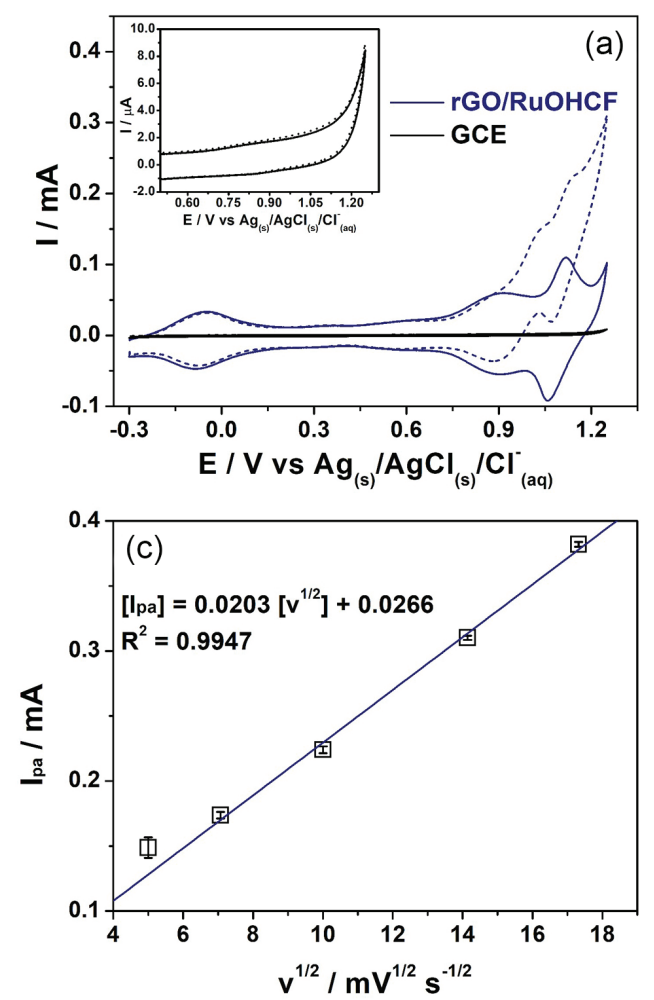

is not followed by any coupled chemical reaction, being purely diffusional, which is proven by the near 0.5 slope value of the logarithmic relationship between the variables (Figure 6d). ${ }^{69}$

The determination of ethanol was performed by amperometry assisted with BIA system. The applied potential, dispensing rate, and dispensing volume were optimized and the chosen values were $1.1 \mathrm{~V}, 213.0 \mu \mathrm{L} \mathrm{s}^{-1}$ and $80 \mu \mathrm{L}$, respectively. Under mechanical stirring, the analytical curves of increasing and decreasing ethanol concentrations were constructed by the injection of the standard analyte (Figure 7a) while the commercial samples were injected between the curves (A and $\mathrm{C}$ signals). The amperogram of the injections from 20.0 to $400.0 \mathrm{mmol} \mathrm{L}^{-1}$ of standard ethanol increases according to the sequential additions and the calibration curves present good linear correlation $(\mathrm{R}>0.98)$ as can be checked in the inset of Figure $7 \mathrm{a}$. Figure $7 \mathrm{~b}$ shows the repeatability test for low $\left(20 \mathrm{mmol} \mathrm{L}^{-1}\right)$ and high concentration $\left(240 \mathrm{mmol} \mathrm{L}^{-1}\right)$ solutions of ethanol and the obtained RSD values were 7 and $11 \%$, respectively. The limits of detection (LOD) and quantification (LOQ) were calculated by $3 \mathrm{~S}_{\mathrm{b}} / \mathrm{S}$ and $10 \mathrm{~S}_{\mathrm{b}} / \mathrm{S}$ (where $\mathrm{S}_{\mathrm{b}}$ is the RSD of 10-times measured blank solution and $\mathrm{S}$ is the slope of the curve), respectively. ${ }^{70}$

The selectivity, reproducibility, and stability of rGO/RuOHCF modified electrode was also tested by
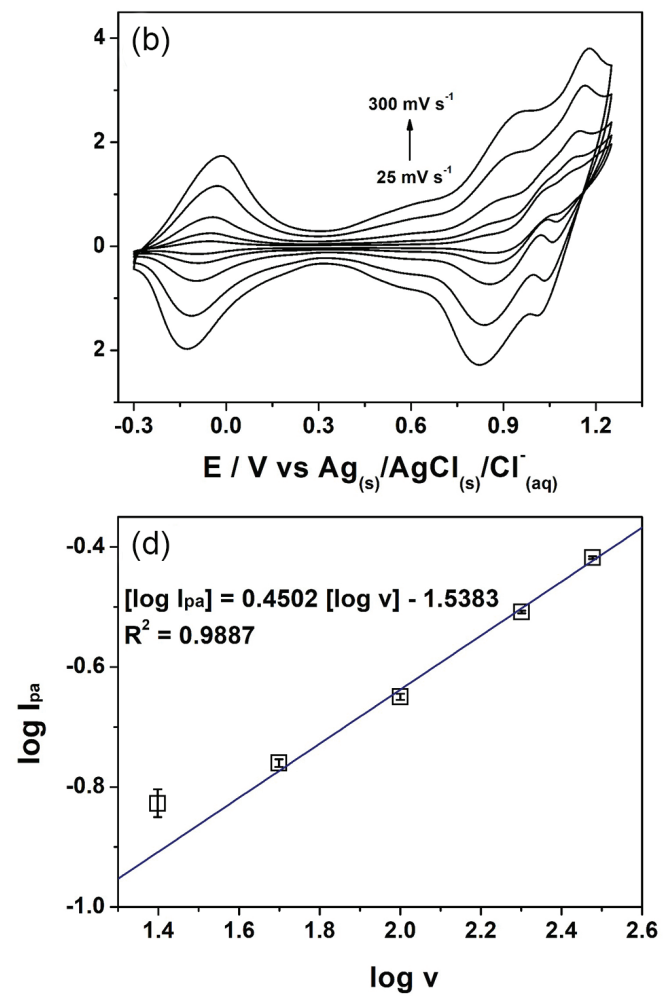

Figure 6. (a) rGO/RuOHCF and GCE (inset) voltammetric behavior $\left(0.1 \mathrm{~mol} \mathrm{~L}^{-1} \mathrm{NaCl}, \mathrm{pH}=1.5\right)$ in $150 \mathrm{mmol} \mathrm{L}^{-1}$ of ethanol (dashed line) and support electrolyte (solid line) solutions; (b) scan rate test $\left(25,50,100,200\right.$, and $\left.300 \mathrm{mV} \mathrm{s}^{-1}\right)$ voltammetry of rGO/RuOHCF modified electrode in the presence of $150 \mathrm{mmol} \mathrm{L}^{-1}$ of ethanol in $0.1 \mathrm{~mol} \mathrm{~L}^{-1} \mathrm{NaCl}$; (c) $\mathrm{I}_{\mathrm{pa}}$ versus $\mathrm{v}^{1 / 2}$ and (d) $\log \mathrm{I}_{\mathrm{pa}}$ versus $\log \mathrm{v}$ plots. 

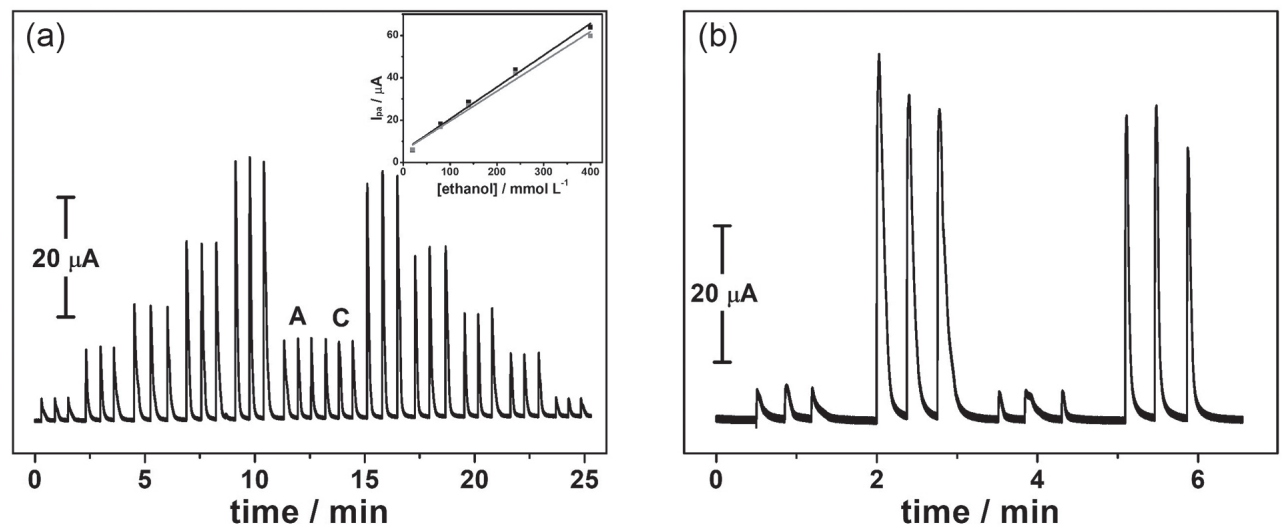

Figure 7. (a) Ethanol BIA/amperometric determination (from 20.0 to $400.0 \mathrm{mmol} \mathrm{L}^{-1}$ ) and calibration plots (inset), and (b) repeatability test by BIA/ amperometry in $0.1 \mathrm{~mol} \mathrm{~L}^{-1} \mathrm{NaCl}$ by rGO/RuOHCF modified electrode. Applied potential: $1.1 \mathrm{~V}$; dispensing rate: $213.0 \mu \mathrm{L} \mathrm{s}{ }^{-1}$; dispensing volume: $80 \mu \mathrm{L}$.

BIA/amperometry under the same conditions. Figure 8a shows the response of four species that could be present in the EtOH fermentation process. The alcohols showed intense peaks, which was expected based on previous works. ${ }^{44,71}$ All species were injected for 3-fold excess, so: methanol showed $89.3 \%$ of EtOH relative current, isopropanol and n-butanol exhibited 378.7 and $384.1 \%$, respectively, while glucose showed only $28.1 \%$. In summary, all other species undergo oxidation processes on the modified electrode, so they can be considered interferents, especially isopropanol and $n$-butanol.

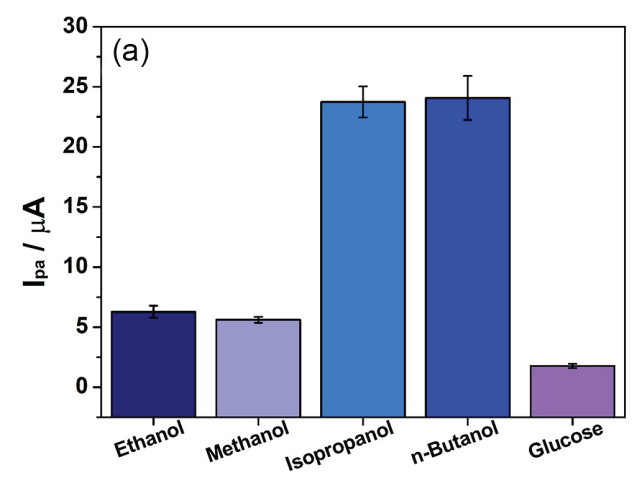

Three $\mathrm{rGO} / \mathrm{RuOHCF}$ modified electrodes were prepared to evaluate its reproducibility. Figure 8 b shows a low peak current difference between them, proving the method of electrode preparation is easily replicable. Also, the material stability was evaluated (Figure 8c) showing good results. It exhibited, on the second day, a slight increase of $11 \%$ of relative current compared to day one, while day three the current intensity keeps practically the same than the day before, proving the $\mathrm{rGO} / \mathrm{RuOHCF}$ modified electrode can be stored for 3 days without losing electroanalytical efficiency.

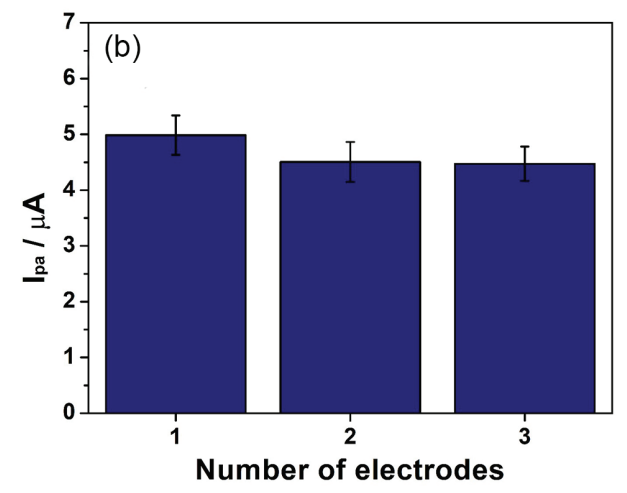

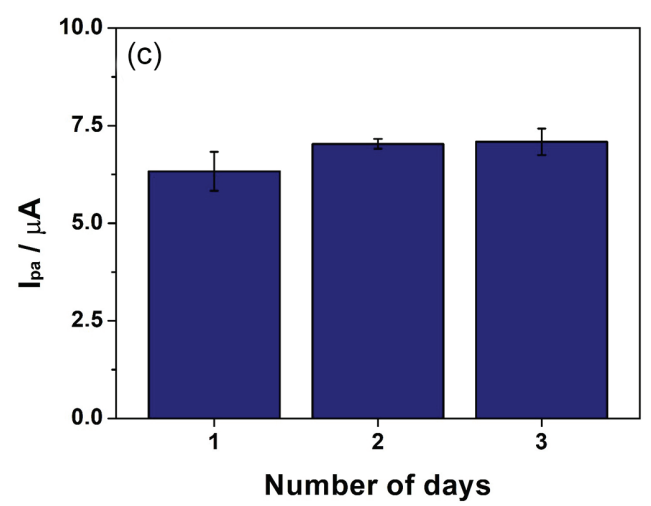

Figure 8. BIA/amperometric results of $\mathrm{rGO} / \mathrm{RuOHCF}$ modified electrode under injection of $20 \mu \mathrm{mol} \mathrm{\textrm {L } ^ { - 1 }} \mathrm{EtOH}$ and $60 \mu$ mol $\mathrm{L}^{-1}$ (3-fold) interfering species $(n=3)(a)$. Response of three different rGO/RuOHCF modified electrodes $\left(20 \mu\right.$ mol L $\left.{ }^{-1} \mathrm{EtOH}\right)(\mathrm{b})$. Stability response of $\mathrm{rGO} / \mathrm{RuOHCF}$ modified electrode for three days $\left(20 \mu \mathrm{mol} \mathrm{L}{ }^{-1} \mathrm{EtOH}\right)(\mathrm{c})$. Supporting electrolyte: $0.1 \mathrm{~mol} \mathrm{~L}^{-1} \mathrm{NaCl}(\mathrm{pH}=1.5)$; applied potential: $1.1 \mathrm{~V}$; dispensing rate: $213.0 \mu \mathrm{L} \mathrm{s}{ }^{-1}$; dispensing volume: $80 \mu \mathrm{L}$. 
Table 1. Electroanalytical parameters of ethanol determination by amperometry of several materials

\begin{tabular}{lccccc}
\hline Material & $\begin{array}{c}\text { Linear range / } \\
\left(\mathrm{mmol} \mathrm{L}^{-1}\right)\end{array}$ & $\begin{array}{c}\text { Sensitivity / } \\
(\mu \mathrm{A} \mathrm{mmol} \mathrm{L})^{-1}\end{array}$ & $\begin{array}{c}\text { LOD / } \\
\left(\mathrm{mmol} \mathrm{L}^{-1}\right)\end{array}$ & $\begin{array}{c}\text { LOQ / } \\
\left(\mathrm{mmol} \mathrm{L}^{-1}\right)\end{array}$ & Reference \\
\hline Gr/Pd-NP & $2.0-210.0$ & - & 2.0 & - & 72 \\
PDDA-[CG-AOx] $]_{5}$ & $0.25-1.5$ & 0.032 & 0.05 & - & 73 \\
ADH/HRP & $10.0-80.0$ & - & 2.85 & 9.50 & 74 \\
RuHCF & $30-400$ & 0.21 & 0.76 & - & 71 \\
MWCNT/RuHCF & $0.2-1.7$ & 1,3 & 0.1 & 1.68 & this work \\
rGO/RuOHCF & $5.0-400.0$ & 0.150 & 0.50 & & 71 \\
\hline
\end{tabular}

LOD: limit of detection; LOQ: limit of quantification; Gr/Pd-NP: graphene/palladium nanoparticles; PDDA-[CG-AOx] $]_{5}$ : poly diallyldimethylammonium chloride-[carboxylated graphene-alcohol oxidase]; ADH/HRP: alcohol dehydrogenase/horseradish peroxidase; RuHCF: ruthenium hexacyanoferrate; MWCNT/RuHCF: multiwalled carbon nanotubes/ruthenium hexacyanoferrate; rGO/RuOHCF: reduced graphene oxide/ruthenium oxide hexacyanoferrate.

Table 1 presents the electroanalytical parameters obtained by various materials in literature ${ }^{67,71-74}$ including this work, which the compared values presented good results, especially regarding the wide linear range. Specifically, when the material prepared in this work is compared with the other ruthenium hexacyanoferrates based sensors presented in Table 1, it became clear that the proposed method results in a higher covering of the substrate by the hexacyanoferrate, with possibility of detection ethanol in a wide concentration range. Moreover, the electrode showed good reproducibility and stability, since this type of study was not explored by the papers mentioned above. ${ }^{67,71-74}$ The facility of the electrode material preparation in contrast to biosensors is also a point to be considered.

The commercial samples analysis of hydrated pharmacy alcohol and cachaça applying the rGO/RuOHCF modified electrode, using the BIA/amperometry method, showed good agreement with the labeled content by the fabricants for both samples. The converted values obtained for hydrated alcohol (A) and cachaça (C) samples injected (see Figure 7a) are exhibited in Table 2. The unity of the hydrated alcohol is shown as ${ }^{\circ}$ INPM, which is the unity used for this substance in Brazil. It means Instituto Nacional de Pesos e Medidas (National Institute of Weights and Measurements) and constitutes the quantity of absolute ethanol in each $100 \mathrm{~g}$ of hydro-alcoholic solution.

Table 2. Concentrations of ethanol found in commercial samples obtained by BIA/amperometry using the $\mathrm{rGO} / \mathrm{RuOHCF}$ modified electrode and respective relative standard deviations $(n=3)$

\begin{tabular}{lcc}
\hline Sample & Labeled & Found \\
\hline Alcohol (A) / ${ }^{\circ}$ INPM & 46 & $45 \pm 1$ \\
Cachaça (C) / \% (v/v) & 39 & $36 \pm 1$ \\
\hline
\end{tabular}

${ }^{\circ}$ INPM: Instituto Nacional de Pesos e Medidas degree.

\section{Conclusions}

This work demonstrated an easy method for the fabrication of reduced graphene oxide/ruthenium oxide hexacyanoferrate nanocomposite material for direct electrode modification. The characterization methods showed the morphological and structural characteristics of the material that acts as a promising material for ethanol electrochemical determination. The electroanalytical results exhibited ample linear range in acidic media using amperometry coupled with a batch injection analysis system. The rGO/RuOHCF modified electrode was successfully tested for ethanol commercial samples demonstrating less than $10 \%$ variation related to labeled by the product fabricators.

\section{Acknowledgments}

The authors would like to thank FINEP, FAPEMIG, CAPES, and CNPq (406529/20167) for financial support. This work was partially supported by the Brazilian Institute of Science and Technology (INCT) in Carbon Nanomaterials. Grupo de Materiais Inorgânicos do Triângulo (GMIT) research group supported by FAPEMIG (APQ-00330-14). We also acknowledge the multiuser laboratory of the Chemistry Institute at the University Federal Uberlândia for providing the equipment and technical support for experiments involving scanning electron microscopy and EDS.

\section{References}

1. de Martinis, B. S.; Ruzzene, M. A. M.; Martin, C. C. S.; Anal. Chim. Acta 2004, 522, 163.

2. Arakawa, T.; Suzuki, T.; Tsujii, M.; Iitani, K.; Chien, P.-J.; Ye, M.; Toma, K.; Iwasaki, Y.; Mitsubayashi, K.; Biosens. Bioelectron. 2019, 129, 245.

3. Bueno, L. H. P.; da Silva, R. H. A.; Azenha, A. V.; Dias, M. C. S.; de Martinis, B. S.; Forensic Sci. Int. 2014, 242, 117.

4. Gamella, M.; Campuzano, S.; Manso, J.; de Rivera, G. G.; López-Colino, F.; Reviejo, A. J.; Pingarrón, J. M.; Anal. Chim. Acta 2014, 806, 1.

5. Huida, L.; Agric. Food Sci. 1982, 54, 137. 
6. Prasad, P. R.; Rama Rao, K. S.; Bhuvaneswari, K.; Praveena, N.; Srikanth, Y. V. V.; Energy Sources, Part A 2008, 30, 1534.

7. Sisco, E.; Robinson, E. L.; Forensic Chem. 2020, 18, 100219.

8. Guerra, J. B.; Araújo, R. A. C.; Pataro, C.; Franco, G. R.; Moreira, E. S. A.; Mendonça-Hagler, L. C.; Rosa, C. A.; Lett. Appl. Microbiol. 2001, 33, 106.

9. Martinelli, L. A.; Filoso, S.; Ecol. Appl. 2008, 18, 885.

10. Jones, A. W.; Mårdh, G.; Änggård, E.; Pharmacol., Biochem. Behav. 1983, 18, 267.

11. López, E. F.; Gómez, E. F.; J. Chromatogr. Sci. 1996, 34, 254.

12. Pontes, H.; de Pinho, P. G.; Casal, S.; Carmo, H.; Santos, A.; Magalhães, T.; Remião, F.; Carvalho, F.; Bastos, M. L.; J. Chromatogr. Sci. 2009, 47, 272.

13. Owuama, C. I.; Ododo, J. C.; Food Chem. 1993, 48, 415.

14. Sanford, C. L.; Mantooth, B. A.; Jones, B. T.; J. Chem. Educ. 2001, 78, 1221

15. Zuriarrain, A.; Zuriarrain, J.; Villar, M.; Berregi, I.; Food Control 2015, 50, 758.

16. Shan, C.; Yang, H.; Han, D.; Zhang, Q.; Ivaska, A.; Niu, L.; Biosens. Bioelectron. 2010, 25, 1504.

17. Huang, H.-Y.; Chen, P.-Y.; Talanta 2010, 83, 379.

18. Nasirizadeh, N.; Ghaani, M.; Shekari, Z.; Shateri-Khalilabad, M.; J. Braz. Chem. Soc. 2016, 27, 1577.

19. Veloso, W. B.; Ribeiro, G. A. C.; da Rocha, C. Q.; Tanaka, A. A.; da Silva, I. S.; Dantas, L. M. F.; Measurement 2020, 155, 107516.

20. Rocha, D. P.; Cardoso, R. M.; Tormin, T. F.; de Araujo, W. R.; Munoz, R. A. A.; Richter, E. M.; Angnes, L.; Electroanalysis 2018, 30, 1386.

21. Ribeiro, G. A. C.; da Rocha, C. Q.; Veloso, W. B.; Dantas, L. M. F.; Richter, E. M.; da Silva, I. S.; Tanaka, A. A.; J. Solid State Electrochem. 2020, 24, 1759.

22. Wang, J.; Taha, Z.; Anal. Chem. 1991, 63, 1053.

23. Cunha, R. R.; Tormin, T. F.; Richter, E. M.; Munoz, R. A. A.; Quim. Nova 2013, 36, 663.

24. Quintino, M. S. M.; Angnes, L.; Electroanalysis 2004, 16, 513.

25. Oliveira, T. C.; Santana, M. H. P.; Banks, C. E.; Munoz, R. A. A.; Richter, E. M.; Electroanalysis 2019, 31, 567.

26. Beitollai, H.; Safaei, M.; Tajik, S.; Int. J. Nano Dimens. 2019 , $10,125$.

27. Guo, N.; Yam, K. M.; Zhang, C.; npj 2D Mater. Appl. 2018, 2 , 1.

28. Ahmad, H.; Fan, M.; Hui, D.; Composites, Part B 2018, 145, 270.

29. Rowley-Neale, S. J.; Randviir, E. P.; Abo Dena, A. S.; Banks, C. E.; Appl. Mater. Today 2018, 10, 218.

30. Toh, S. Y.; Loh, K. S.; Kamarudin, S. K.; Daud, W. R. W.; Chem. Eng. J. 2014, 251, 422.

31. Chua, C. K.; Pumera, M.; Chem. Soc. Rev. 2014, 43, 291.

32. Chen, W.; Yan, L.; Bangal, P. R.; Carbon 2010, 48, 1146.
33. Moradi Golsheikh, A.; Huang, N. M.; Lim, H. N.; Zakaria, R.; Yin, C.-Y.; Carbon 2013, 62, 405.

34. Shi, R.; Liang, J.;Zhao,Z.; Liu, A.; Tian, Y.; Talanta 2017, $169,37$.

35. Zhou, N.; Li, J.; Chen, H.; Liao, C.; Chen, L.; Analyst 2013, $138,1091$.

36. Chen, D.; Zhuang, X.; Zhai, J.; Zheng, Y.; Lu, H.; Chen, L.; Sens. Actuators, B 2018, 255, 1500.

37. Zhuang, X.; Chen, D.; Zhang, S.; Luan, F.; Chen, L.; Microchim. Acta 2018, 185, 166.

38. Thirumalraj, B.; Rajkumar, C.; Chen, S.-M.; Veerakumar, P.; Perumal, P.; Liu, S.-B.; Sens. Actuators, B 2018, 257, 48.

39. Luan, F.; Zhang, S.; Chen, D.; Wei, F.; Zhuang, X.; Microchem. J. 2018, 143, 450.

40. Zhang, W.; Zhao, Y.; Malgras, V.; Ji, Q.; Jiang, D.; Qi, R.; Ariga, K.; Yamauchi, Y.; Liu, J.; Jiang, J.-S.; Hu, M.; Angew. Chem., Int. Ed. 2016, 55, 8228.

41. Karyakin, A. A.; Curr. Opin. Electrochem. 2017, 5, 92.

42. Karyakin, A. A.; Karyakina, E. E.; Russ. Chem. Bull. 2001, 50, 1811.

43. Kumar, A. S.; Zen, J.-M.; Electroanalysis 2004, 16, 1211.

44. Chen, S.-M.; Lu, M.-F.; Lin, K.-C.; J. Electroanal. Chem. 2005, $579,163$.

45. Shaidarova, L. G.; Ziganshina, S. A.; Tikhonova, L. N.; Budnikov, G. K.; J. Anal. Chem. 2003, 58, 1144.

46. Borges, P. H. S.; Catto, A. C.; Longo, E.; Nossol, E.; J. Electroanal. Chem. 2020, 878, 114558.

47. Pedrotti, J. J.; Angnes, L.; Gutz, I. G. R.; Electroanalysis 1996, $8,673$.

48. Rasband, W. S.; ImageJ, 1.53e; U. S. National Institutes of Health, Bethesda, Maryland, USA, 2020.

49. Silva, R. A. B.; Montes, R. H. O.; Richter, E. M.; Munoz, R. A. A.; Food Chem. 2012, 133, 200.

50. Chen, L.; Tang, Y.; Wang, K.; Liu, C.; Luo, S.; Electrochem. Commun. 2011, 13, 133.

51. Quezada-Renteria, J. A.; Ania, C. O.; Chazaro-Ruiz, L. F.; Rangel-Mendez, J. R.; Carbon 2019, 149, 722.

52. Guo, H.-L.; Wang, X.-F.; Qian, Q.-Y.; Wang, F.-B.; Xia, X.-H.; ACS Nano 2009, 3, 2653.

53. Li, M.; He, H.; Appl. Surf. Sci. 2018, 439, 612.

54. Raoof, J. B.; Ojani, R.; Baghayeri, M.; Anal. Methods 2011, 3, 2367.

55. Ding, Y.; Gu, G.; Xia, X.-H.; J. Solid State Electrochem. 2008, $12,553$.

56. Neale, Z. G.; Liu, C.; Cao, G.; Sustainable Energy Fuels 2020 , 4, 2884.

57. Dattilo, D.; Dietze, U.; Hsu, J.-W.; Proc. SPIE 2015, 9635, 96351B.

58. Kim, J.-Y.; Kim, K.-H.; Yoon, S.-B.; Kim, H.-K.; Park, S.-H.; Kim, K.-B.; Nanoscale 2013, 5, 6804.

59. Gimenes, D. T.; Nossol, E.; Electrochim. Acta 2017, 251, 513. 
60. Dresselhaus, M. S.; Jorio, A.; Hofmann, M.; Dresselhaus, G.; Saito, R.; Nano Lett. 2010, 10, 751.

61. How, G. T. S.; Pandikumar, A.; Ming, H. N.; Ngee, L. H.; Sci. Rep. 2014, 4, 5044.

62. Gigot, A.; Fontana, M.; Pirri, C. F.; Rivolo, P.; Materials 2018 , $11,57$.

63. Pang, H.; Zhang, Y.; Cheng, T.; Lai, W.-Y.; Huang, W.; Nanoscale 2015, 7, 16012.

64. Tुucureanu, V.; Matei, A.; Avram, A. M.; Crit. Rev. Anal. Chem. 2016, 46, 502

65. Eluyemi, M. S.; Eleruja, M. A.; Adedeji, A. V.; Olofinjana, B.; Fasakin, O.; Akinwunmi, O. O.; Ilori, O. O.; Famojuro, A. T.; Ayinde, S. A.; Ajayi, E. O. B.; Graphene 2016, 5, 143.

66. Singh, M. K.; Titus, E.; Krishna, R.; Hawaldar, R. R.; Goncalves, G.; Marques, P.; Gracio, J.; J. Nanosci. Nanotechnol. 2012, 12, 6731.

67. Costa, W. M.; Cardoso, W. S.; Marques, E. P.; Bezerra, C. W. B.; Ferreira, A. A. P.; Song, C.; Zhang, J.; Marques, A. L. B.; J. Braz. Chem. Soc. 2013, 24, 651.
68. Zhang, S.; Zhuang, X.; Chen, D.; Luan, F.; He, T.; Tian, C.; Chen, L.; Microchim. Acta 2019, 186, 450.

69. Timbola, A. K.; Souza, C. D.; Soldi, C.; Pizzolatti, M. G.; Spinelli, A.; J. Appl. Electrochem. 2007, 37, 617.

70. Stefano, J. S.; de Lima, A. P.; Montes, R. H. O.; Richter, E. M.; Muñoz, R. A. A.; J. Braz. Chem. Soc. 2012, 23, 1834.

71. Lin, K.-C.; Hong, C.-P.; Chen, S.-M.; Int. J. Electrochem. Sci. 2012, 7, 11426.

72. Kumar, M. A.; Patnaik, S. G.; Lakshminarayanan, V.; Ramamurthy, S. S.; Anal. Lett. 2017, 50, 350.

73. Prasanna Kumar, S.; Parashuram, L.; Suhas, D. P.; Krishnaiah, P.; Mater. Sci. Energy Technol. 2020, 3, 159.

74. Pisoschi, A. M.; Pop, A.; Serban, A. I.; Negulescu, G. P.; J. Electroanal. Chem. 2012, 671, 85.

Submitted: December 17, 2020 Published online: February 26, 2021 